\title{
EFFECTS OF M OISTURE CONTENT AND HEAT TREATMENT ON PEROXIDE VALUE AND OXIDATIVE STABILITY OF UN-REFINED SESAME OIL
}

$$
\text { A kinoso } \mathrm{R}^{* 1}, \mathrm{AboabaSA}^{2} \text { and TM A Olayanju }{ }^{3}
$$

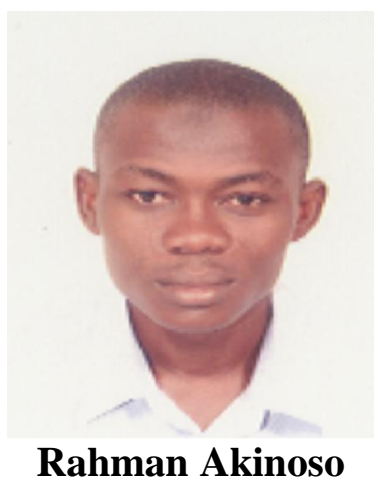

*Corresponding author e mail: akinoso2002@yahoo.com

1. Department of Food Technology, Faculty of Technology, University of Ibadan, Nigeria.

2. Department of Chemistry, Faculty of Science, University of Ibadan, Nigeria.

3. Department of Agricultural Engineering, College of Engineering, University of Agriculture Abeokuta, Nigeria. 


\section{ABSTRACT}

Sesame (Sesamum indicum L) is one of the oldest cultivated plants. Its seed contains about $42-54 \%$ quality oil, 22-25\% protein, 20-25\% carbohydrates and 4-6\% ash. This composition varies with genetic and environmental factors. Conditioning of oil seeds which include roasting, flaking, size reduction, cooking, pre-pressing and drying, is an important operation in the production line of sesame oil. This work investigated effects of initial moisture content, roasting duration and temperature on initial Peroxide Value (PV) and Oxidative Stability (OS) of un-refined sesame oil using response surface methodology. Goza-25, a variety of sesame seed that is commercially cultivated in Nigeria was used for the study. Initial moisture content levels were $4,7,10,13$ and $16 \%$ wet basis (wb). Roasting duration and temperature levels were 5, 10, 15, 20 and 25 minutes, and 50, 70, 90, 110 and $130{ }^{\circ} \mathrm{C}$ respectively. The recorded minimum and maximum PV were 3.9 and $15.4 \mathrm{meq} / \mathrm{kg}$ respectively. Mean value was $9.85 \pm 3.9 \mathrm{meq} / \mathrm{kg}$. Peroxide value increased with increasing moisture content and reduced with increasing roasting duration. Analysis of variance and regression analysis of obtained data showed that application of quadratic model to predict effect of initial moisture content, roasting duration and temperature on peroxide value is significant at $\mathrm{p} \leq 0.05$. Within the studied range, $13 \mathrm{~h}$ was the minimum OS recorded while maximum were $63.3 \mathrm{~h}$. Mean of the data was $38.37 \pm$ 16.02. Using the conversion factor of one hour of an active oxygen hour as being equivalent to 15 days; the expressed sesame oil in its present form will retain its quality for a maximum period of 949 days. Rise in roasting temperature and duration increased the oxidative stability, a reverse was observed with initial moisture content. High moisture content reduced the quality and storage life while heat treatment increased both the initial quality and storage life of the mechanically expressed oil. Peroxide value and oxidative stability of crude sesame oil significantly ( $\mathrm{p} \leq 0.05)$ depend on moisture content of the seed, roasting duration and temperature.

K ey words: Sesame, Oil, Crude, Oxidation, Storage 


\section{INTRODUCTION}

Sesame (Sesamum indicum L) also known as sesamum, gingelly, sim sim, beniseed and til is the one of the oldest cultivated plants [1]. Its seed contains about 42-54\% quality oil, 22-25\% protein, 20-25\% carbohydrates and 4-6\% ash [2]. The hull contains large quantities of oxalic acid, crude fiber, calcium and other minerals. When the seed is properly dehulled, the oxalic acid content is reduced from about $3 \%$ to less than $0.25 \%$ of the seed weight [3]. The composition varies with genetic and environmental factors [4]. The production figures of this crop in Nigeria are on steady increase. According to Central Bank of Nigeria 2008 annual report, there was a rise in production of sesame seed from 98,000,000 to 152,000,000 kg from 2003 to 2007 [5].

Sesame seed oil is a natural salad oil, requiring little or no winterization, and is one of the few vegetable oils that can be used directly without refining [6]. Because of the excellent quality of the edible oil it produces, sesame is often called queen of the oil seed crops. The meal remaining after oil extraction has unique nutritional properties. It is rich in methionine, cysteine and tryptophan. Sesame protein complements very well most oil seeds and vegetable proteins. The seed cake is also an excellent protein supplement in the animal feed industry. Sesame oil contains about $80 \%$ unsaturated fatty acids with oleic and linoleic as the major fatty acids present in approximate ratio of $37.2 \%$ and $46.3 \%$ respectively [7]. This enables it to remain as a liquid at room temperature. Among the commonly used vegetable oils, sesame oil is known to be most resistant to oxidative rancidity [1]. It also exhibits noticeably greater resistance to autoxidation than would be expected from its content of tocopherols (vitamin E). Stability of unrefined sesame oil is attributed to the presence of endogenous phenolic antioxidants viz. sesamin, sesamolin and sesamol [8].

Preferences for fat and oil products with fresh bland flavours and odours require quality and rancidity evaluations both during development and after processing. Peroxide value (PV) is one of the most widely used chemical tests for the determination the quality of fat and oil. The PV is a measure of rancidity in its early stage and shows good correlation with organoleptic flavour scores [9]. Use of PV as flavor quality indicator is only reliable during the initial stages of lipid oxidation because the peroxide value increases to a maximum and then decreases as storage time increases [10]. In order to guard against errors, oil and fat undergo oxidative stability test. Oxidative stability test is a good quality assessment parameter that complements PV analysis [11]. Most fats and oils products are tested for flavour stability as part of quality control programmes to ensure that customer specification limits are satisfied. Studies to determine oxidative stability of sesame and its byproducts including dehulled seed, coats and sesame oil have been reported $[8,12,13$, 14]. These reports showed that oxidative stability of oil and by-products was dependent on processing techniques and variety of seeds. The importance of seed variety on quality and oil content has also been reported. The report revealed that the black seed types contained less oil compared to white and brown seeded strains. Similar differences were also seen in sesamin content [15]. 
Conditioning of oil seeds is an important operation in the production line of sesame oil. These activities include roasting, flaking, size reduction, cooking, pre-pressing and drying. Dehydrating and roasting of sesame seeds before oil expression improves sesame oil yield and quality [16, 17]. There is need to establish the degree of influence of the parameters on peroxide value and storage life of the expressed crude sesame oil. Thus this work aimed at investigating effects of moisture content, roasting duration and temperature on initial quality and oxidative stability of un-refined sesame oil using response surface methodology. Goza-25, a variety of sesame seed that is commercially cultivated in Nigeria was used for the study.

\section{MATERIALS AND METHODS}

\section{Experimental Design}

The experiment was designed using central composite rotatable design of response surface methodology [18]. Initial moisture content, roasting duration and temperature were independent variables while peroxide value and oxidative stability of the oil were the dependent variable. Fixing of independent parameters levels were based on preliminary work [17]. Fifteen level combinations were used. Last point was repeated 6 times (Table 1). A total of 20 runs were produced.

\section{M aterial Preparation}

Raw sesame seed (Goza-25) was sourced from National Cereal Research Institute Badegi, Nigeria. It was cleaned manually to remove foreign materials which include; oversize materials like leaves, sticks and stems; undersize materials such sand and dust; same size material like hulls, empty shell of grains and stone. The process line is shown as Figure 1. 
Raw Sesame Seed<smiles></smiles><smiles>CC[C@@H](C)OC(C)=O</smiles>

(Varied moisture content, roasting duration and temperature)

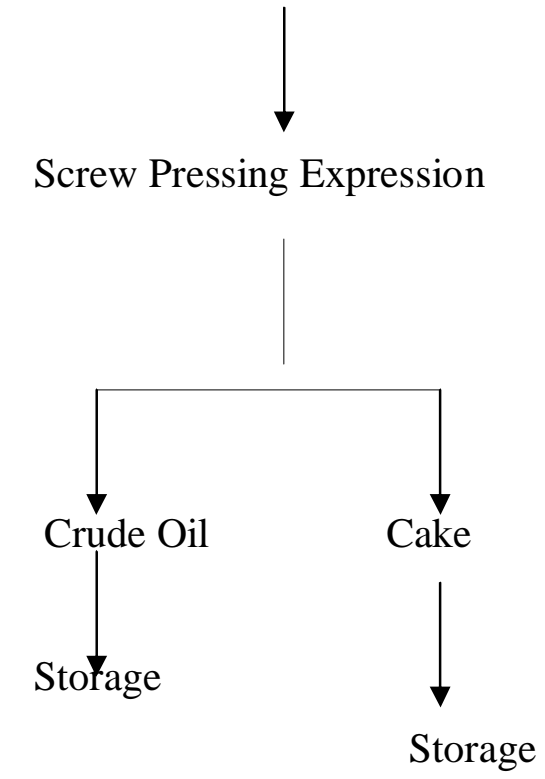

Figure 1: Flow chart for mechanical expression of sesame oil.

\section{M oisture Content}

Initial moisture content of the seed was determined using standard method for oil seed [19]. Three samples each weighing $15 \mathrm{~g}$ was placed in an oven set at $130^{\circ} \mathrm{C}$ for $6 \mathrm{hrs}$. The samples were then cooled in a glass jar containing silica gel as desiccant. The dried samples were weighed and the difference in weight before and after drying was taken to be moisture loss. Ratio of moisture loss to weight of wet material in percentage was recorded as moisture content wet basis. The desired moisture content levels were achieved by adding calculated volume of distilled water as obtained from equation 1 to sesame seed. To ensure uniform moisture content, each sample was thoroughly mixed, wrapped and separately sealed in polyethylene bag. The samples were kept at $5{ }^{\circ} \mathrm{C}$ in a refrigerator for 12 hours to enable the moisture to distribute uniformly throughout the samples. Five moisture content levels each were prepared. They were 4, 7, 10, 13 and $16 \%$ wet basis (wb). 
$Q=A(b-a) /(100-b) \cdots \cdots \cdots \cdots \cdots \cdots \cdots$

where

A - Initial mass of the sample

a - Initial moisture content of the sample, \% wet basis (wb)

b - Final (desired) moisture content of sample \% wb

$\mathrm{Q}$ - Mass of water to be added $\mathrm{kg}$.

\section{Pre-H eat Duration and Temperature of R oasting}

Roasting temperature stability was achieved by reported method [20]. The product's initial temperatures were raised to equilibrium with roasting temperature. This was achieved by wrapping them in polythene bags and placed in convection oven (Model LDO-25OF, Win Science, Seoul, Korea) at desired roasting temperature level. These samples were later heated by spreading thinly on a heat conductor tray in an oven at a preset temperature. The samples were heated at specified temperature and time. Stop watch was used to monitor the time. Roasting durations were 5, 10, 15, 20 and 25 minutes while roasting temperatures were $50,70,90,110$ and $130^{\circ} \mathrm{C}$.

\section{Oil Expression}

The expeller used was Tite 002 manufactured by Tiny Tech Plant, India, of a rated capacity of $180 \mathrm{~kg} / \mathrm{h}$, powered by a $30 \mathrm{~kW}$ electric motor with interchangeable speed. It was made up of a helical thread that revolves within a stationary perforated cylinder. The experimental procedure was by running the screw press for about 3 minutes before loading the pre-treated samples of sesame seed. The oil seed was forced through the barrel by the action of the revolving worms. The volume axially displaced by the worm diminished from the feeding end to the discharge end, thus compressing the meal as it passes through the barrel. The expelled oil drained through the perforation of the lining bars of the barrel, while the de-oiled cake was discharged through the annular orifice. Expressed oil was collected and clarified by allowing it to stand for $96 \mathrm{~h}$. Clarified oil was bottled and labeled as samples.

\section{Peroxide V alue (PV)}

The peroxide value of un-refined sesame oil was determined by a modified American Oil Chemists' Society (AOCS) standard method Cd 8-53 [21]. About 5-ml of oil was placed on a test paper (United States Patent 4098575). About 10-ml amount of water was added to the paper on which the oil has been placed. The intensity of the blue color developed on the test paper is proportional to the peroxide value of the oil. Colour of the paper was compared to a predetermined standard [22].

\section{Oxidative Stability (OS)}

Oxidative stability was evaluated by AOCS method Cd 12b-92 [21], using Rancimat 679 apparatus (Metrohm AG, Herison, Switzerland). The evaluation procedure was performed by placing 2 grams of the oil sample into the sample tube, which was preheated to $120^{\circ} \mathrm{C}$ connected on one side to the air source and on the other side to 50- 
$\mathrm{ml}$ cell of deionized water. The conductance of the water was measured automatically over time with data logger. Stability was expressed as the oxidation induction period in hours.

\section{Data Analysis}

The experimental procedures were repeated 3 times for each treatment; mean values were recorded as obtained data. Interactions between the independent and dependent variables were analyzed by response surface methodology (RSM) using DesignExpert@ 7 software. Analysis of variance (ANOVA) was carried out and model equations were developed using the software package.

\section{RESULTS}

\section{Peroxide Value}

The recorded minimum and maximum peroxide values (PV) were 3.9 and 15.4 $\mathrm{meq} / \mathrm{kg}$ respectively. Mean value was $9.85 \pm 3.9 \mathrm{meq} / \mathrm{kg}$. ANOVA on the obtained data showed that application of quadratic model to predict effect of independent variables on peroxide value is significant at $p \leq 0.05$. Moisture content $(\alpha)$, roasting duration $(\beta)$, roasting temperature $(\delta)$, their $2^{\text {nd }}$ order $\alpha^{2}, \beta^{2}, \delta^{2}$ were significant model terms. Also, lack of fit test for the quadratic model is significant at $\mathrm{p} \leq 0.05$. Mathematical expression of the interaction of the actual value is as shown in equation 2. Coefficient of determination $\mathrm{R}^{2}$ is 0.9 . As seen in the equation $2, \alpha, \beta, \delta, \alpha \beta, \alpha \mathrm{C}$, $\beta \delta$ have positive influence on PV while $\alpha^{2}, \beta^{2}$ and $\delta^{2}$ effects were negative. Moisture content effect is the highest while $2^{\text {nd }}$ order of roasting temperature is the lowest.

$$
\begin{aligned}
& \mathrm{PV}=-22.87+1.87 \alpha+0.63 \beta+0.49 \delta+0.05 \alpha \beta+7.92 \times 10^{-3} \alpha \delta \\
& +6.5 \times 10^{-3} \beta \delta-0.12 \alpha^{2}-0.06 \beta^{2}-4.11 \times 10^{-3} \delta^{2} \ldots \ldots \ldots \ldots \ldots . .2
\end{aligned}
$$

Figures 2-4 illustrate the response of the variable inputs using contour plot. Keeping roasting temperature at $90^{\circ} \mathrm{C}, \mathrm{PV}$ increased with increasing moisture content and decreased with increasing roasting duration (Fig. 2). At constant roasting duration of 15 minutes, increasing moisture content also increased PV while the reverse was observed on roasting temperature (Fig. 3). However, at fixed moisture of $10 \% \mathrm{wb}$, PV decreased with increasing both roasting duration and temperature (Fig. 4). 


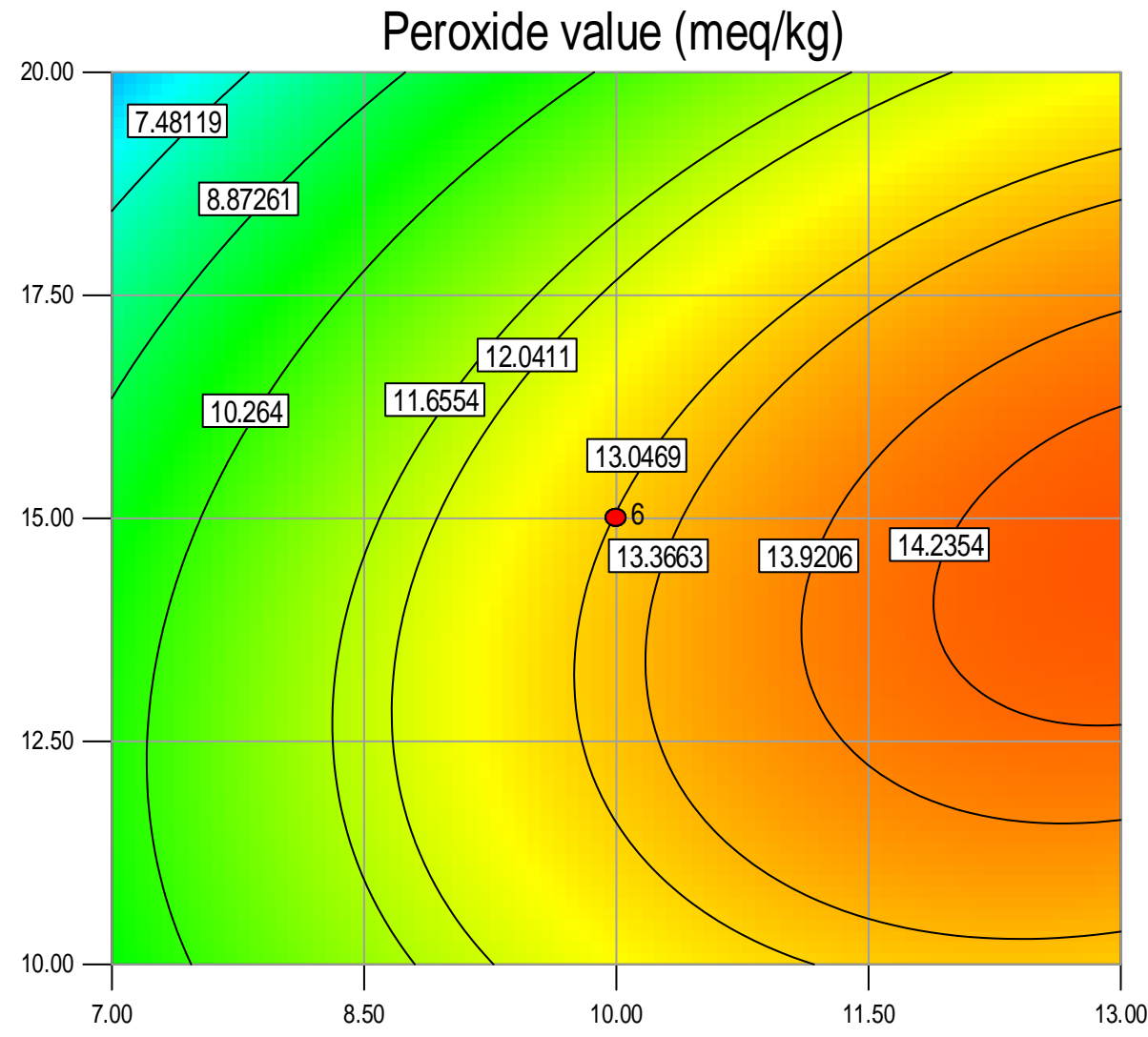

$\mathrm{X} 1$ : Moisture content (\%wb)

$\mathrm{X} 2$ : Roasting duration ( $\mathrm{min}$ )

Figure 2: Dependence of peroxide value on moisture content and roasting duration 


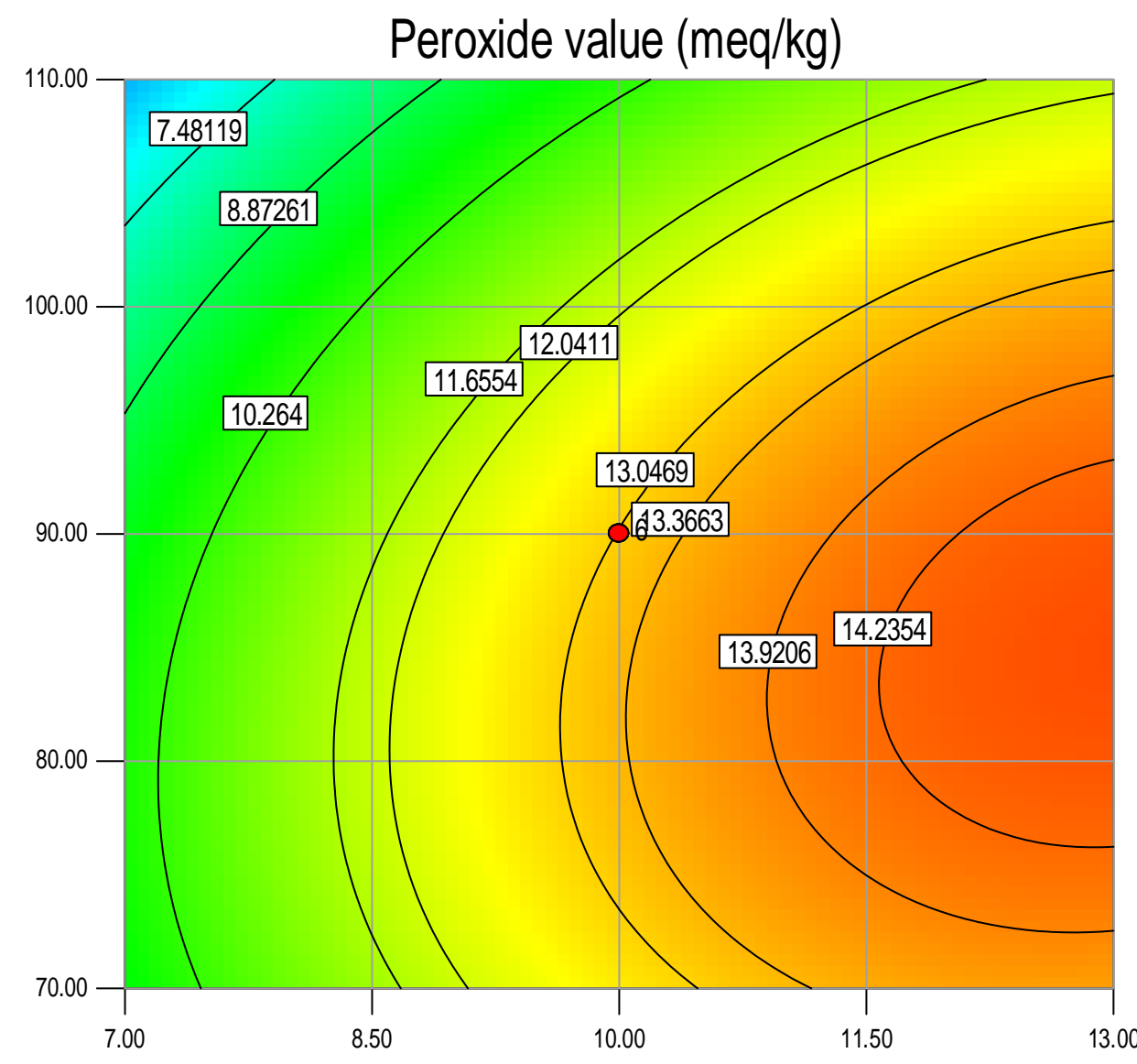

$\mathrm{X} 1$ : Moisture content (\%wb)

X2: Roasting temperature (oC)

Figure 3: Dependence of peroxide value on moisture content and roasting temperature. 


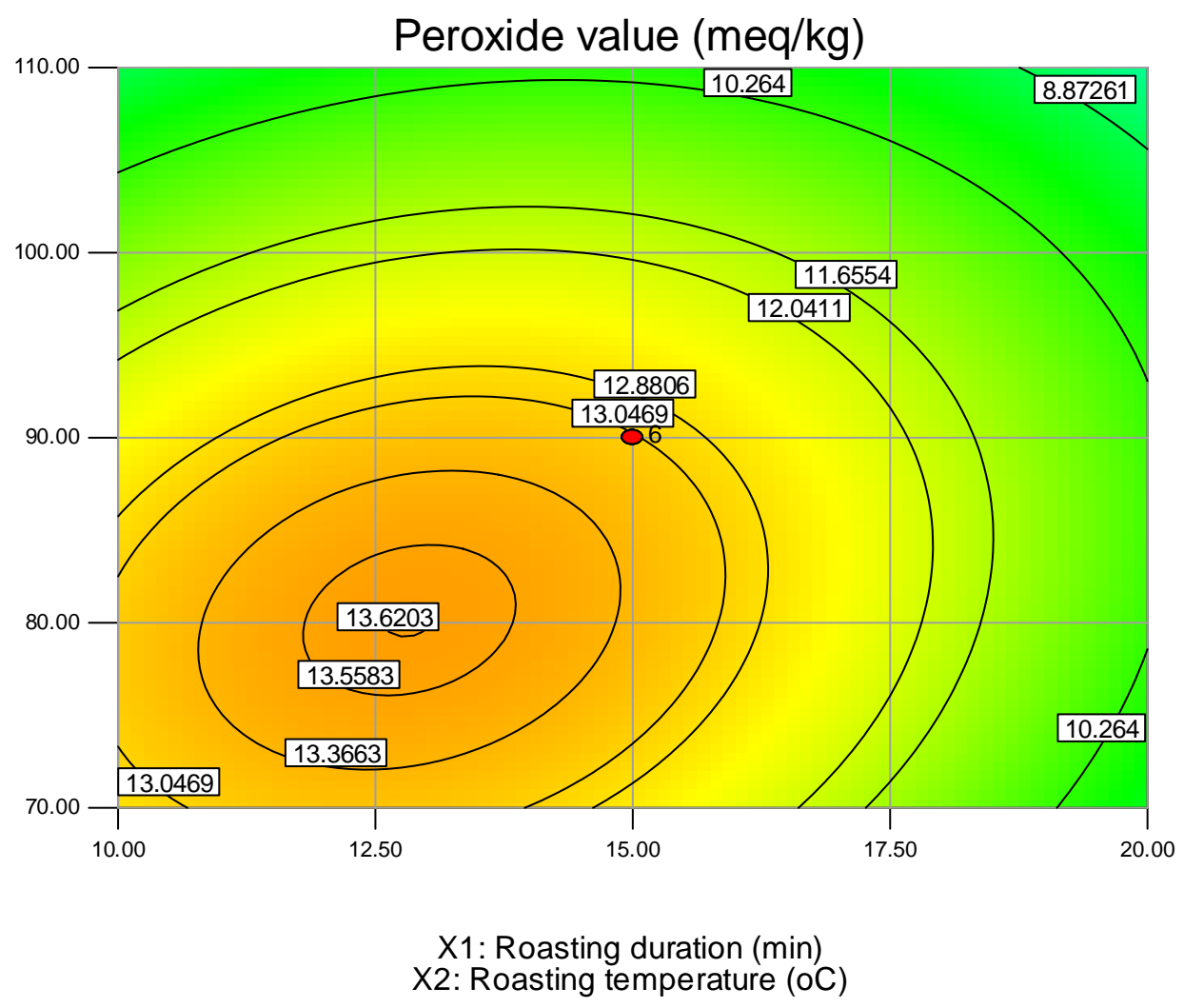

Figure 4: Dependence of peroxide value on roasting duration and temperature.

Oxidative stability (OS)

Within the studied range, $13 \mathrm{~h}$ was the minimum oxidative stability (OS) recorded while maximum was $63.3 \mathrm{~h}$. Mean of the data was $38.37 \pm 16.02$. Statistical analysis of the data revealed that a response surface quadratic model was fit to express the effect of moisture content and heat treatment on oxidative stability of crude sesame. From the model terms, only moisture content, roasting temperature, $2^{\text {nd }}$ of roasting duration and temperature were significant at $\mathrm{p} \leq 0.05$. Final equation in terms of actual factors is as shown in equation 3. Coefficient of determination, $\mathrm{R}^{2}$ of the model was 0.78 .

$$
\begin{aligned}
& \mathrm{OS}=+174.45-9.05 \alpha-4.2 \beta-1.77 \delta-0.16 \alpha \beta-2.08 \times 10^{-4} \alpha \delta \\
& -4.13 \times 10^{-3} \beta \delta+0.43 \alpha^{2}+0.23 \beta^{2}+0.01 \delta^{2} \ldots \ldots \ldots \ldots \ldots \ldots \ldots \ldots . .3 .
\end{aligned}
$$

Moisture content, roasting duration and temperature, and their interactions had negative effect on OS of sesame oil, although only effects of moisture content and roasting temperature were significant at $p \leq 0.05$. Positive influences were observed on $2^{\text {nd }}$ order of all the independent variables. Graphical outputs of response surface showed how OS responded to varying treatment were illustrated as Figs. 5-7. Saddle point of the contours is $26.6 \mathrm{~h}$. The observed contour plots were also parabolic but in opposite direction to what was obtainable in PV graphs. 


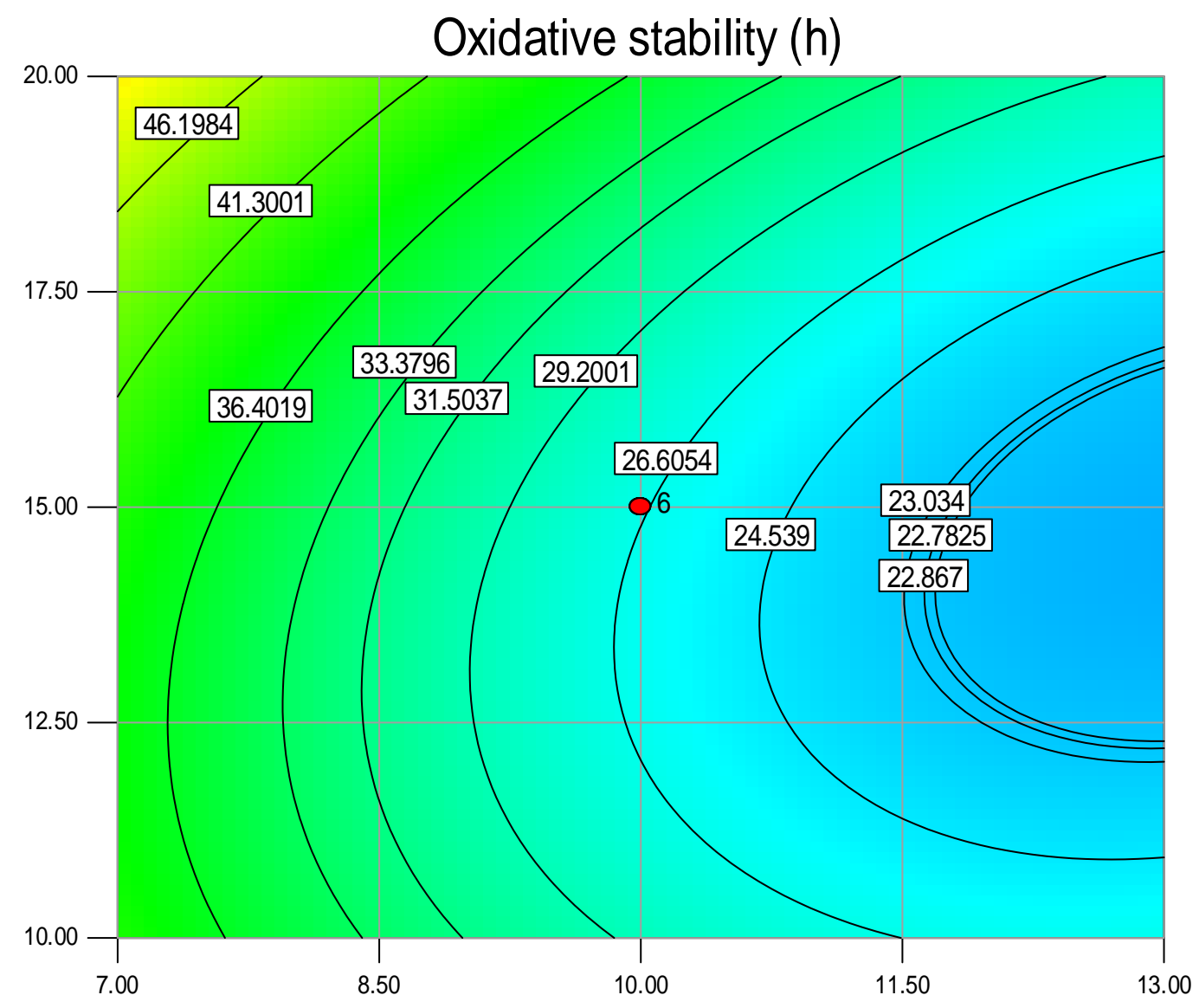

X1: Moisture content (\%wb)

$\mathrm{X} 2$ : Roasting duration ( $\mathrm{min}$ )

Figure 5: Dependence of oxidative stability on moisture content and roasting duration 


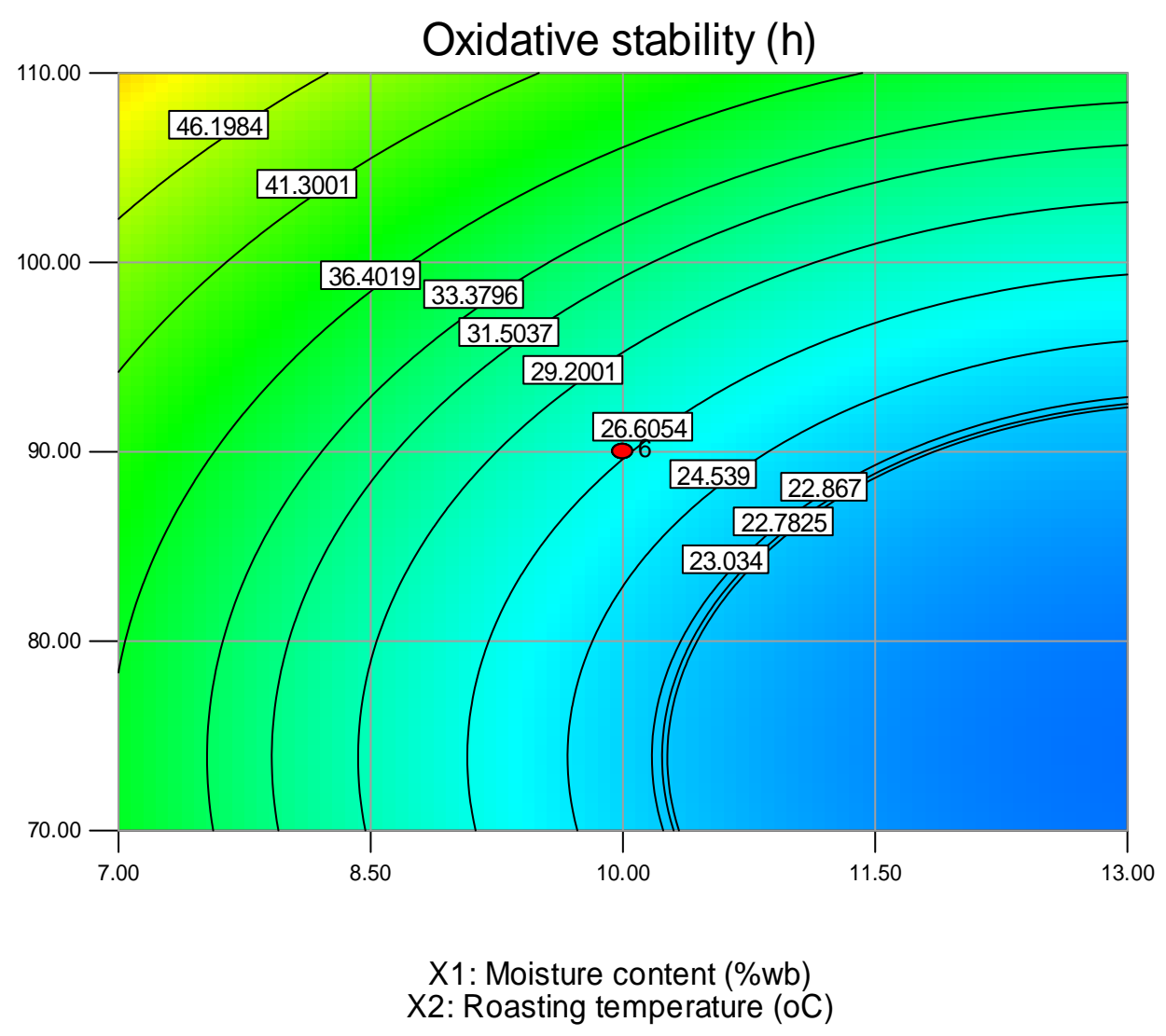

Figure 6: Dependence of oxidative stability on moisture content and roasting temperature 


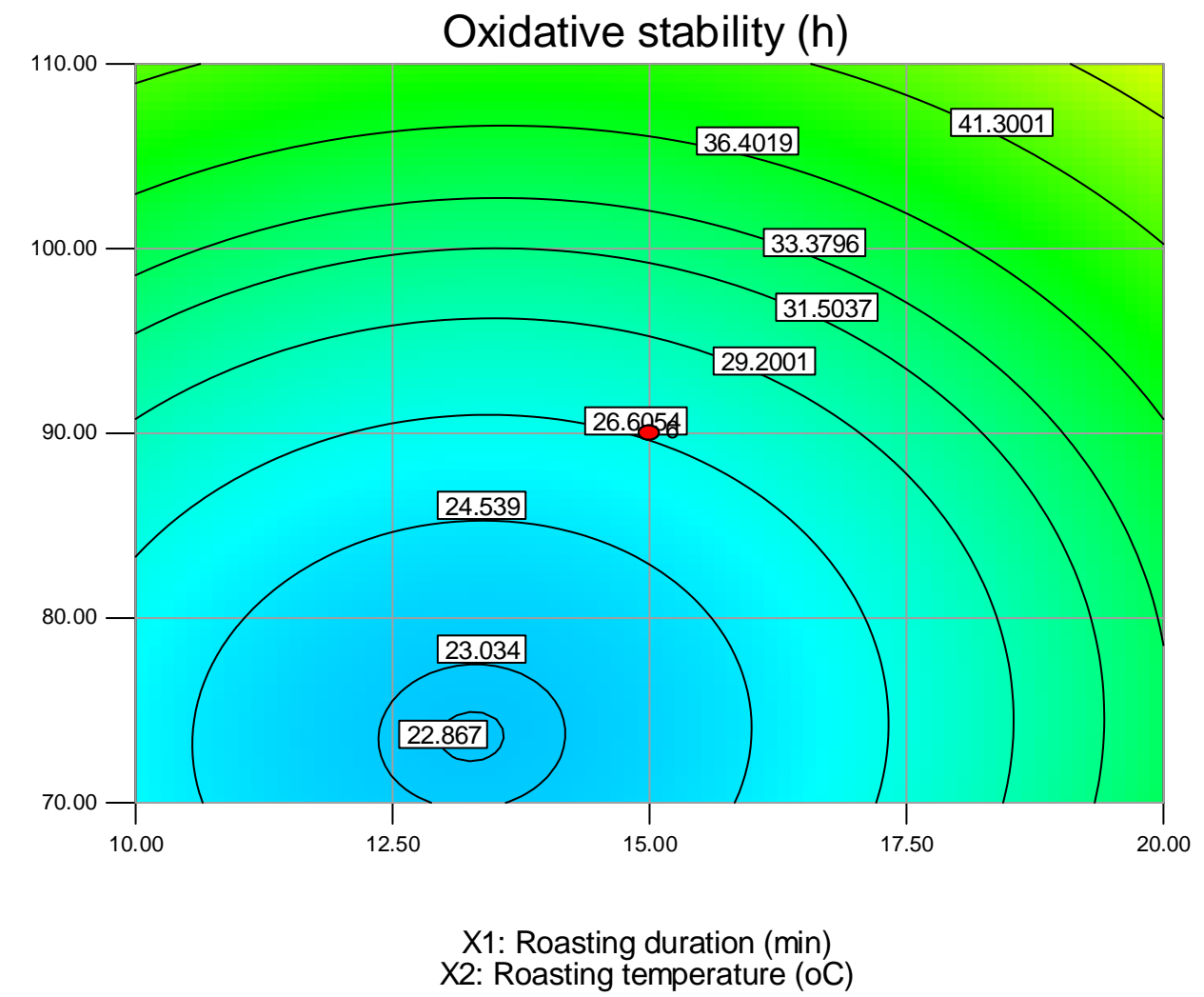

Figure 7: Dependence of oxidative stability on roasting duration and temperature

\section{DISCUSSIONS}

\section{Peroxide Value (PV)}

From a related work, PV of $5 \mathrm{meq} / \mathrm{kg}$ was found in a sample of oil extracted from sesame seed roasted at $180^{\circ} \mathrm{C}$ for 30 minutes [23]. The significance of the analysis of variance and regression at $95 \%$ confidence level was an indication that a response surface quadratic model was appropriate to express the relationship between moisture content, roasting duration and temperature of sesame and the resultant peroxide value of the expressed sesame oil. Thermal properties of biological material are dependent on its moisture content [24]. Reason for highest influence of moisture content may be associated with this fact. It is known that factors such as temperature, light, moisture, metals and oxygen affect rate of oxidation. This is a major cause of their deterioration [2].

Contour plot is a 2D representative of response for selected factors. These plots help to visualize the shape of the response surface and give useful information about model fitted. Outlook of these Figures $(2$ - 4) showed parabolic shape of contours. It indicated that the center point is saddle and it neither maximum nor a minimum point. 
This explains why response surface quadratic model is fit to predict PV of the oil as affected by moisture content and heat treatments. As expected, a biological material like sesame displays non-homogeneous characteristics. Oxidation of lipids is a major cause of their deterioration, and moisture content naturally accelerates rate of oxidative reaction [25]. This gave insight to the displayed trend of the contour plots. Formation of PV is a chemical reaction, and like most reactions, it is influenced by heat and some other factors. At high temperature, there is continuous generation of sesamol [14]. Thus reduction in PV level at high temperature may be deduced to the formation of sesamol, an antioxidant.

\section{Oxidative stability (OS)}

One hour of an active oxygen hour is equivalent to 15 days [9]. Using this conversion factor, the oil in its present form will retain quality for maximum period of 949 days. Stability of sesame oil fortified with sesamolin and sesamol after 94 hours of activation has also been reported [8]. In comparison, sesame oil is more stable than safflower [26] and crude meadow foam press oil [11].This concurs with work of [27] who concluded that among the commonly used vegetable oils, sesame oil is most resistant to oxidative rancidity. The remarkable stability of un-refined sesame oil is now widely attributed to presence of endogenous phenolic antioxidants, viz., sesamin, sesamolin and sesamol. Ability of products to resist oxidative and hydrolytic deterioration during storage is a prime factor in determining the quality of edible oils.

Dependence of oxidative stability of sesame oil on roasting temperature and time was also reported [28]. Formation of sesamol, one of the natural antioxidants presents in sesame oil increases with increasing roasting temperature [29]. Thus, significant influence of heat treatment on thermal oxidation of the compound might have cause the observed behavior. The trend of plots (Figs. 5 -7) was confirmation that the lower the PV of an oil, the better the quality and invariably longer the shelf life as represented by oxidative stability. It is an established fact that shelf life of most products depend on their initial quality before storage.

\section{CONCLUSION}

Initial quality and storage life of crude sesame oil significantly ( $\leq \leq 0.05)$ depend on the initial moisture content of sesame seed, duration and temperature of heating. High moisture content reduced the quality and storage life while heat treatment increased both the initial quality and storage life of the mechanically expressed oil. From this work, it could be inferred that sesame oil expressed from Goza-25 variety of sesame can maintain its flavour for 949 days without minimum sign of rancidity. Relationship between peroxide value and oxidative stability (responses) and the variables (moisture content, roasting duration and temperature) can be expressed mathematically using response surface quadratic models. 
Table 1: The treatments and responses of the experiment

\begin{tabular}{ccccccccc}
\hline $\mathrm{S} / \mathrm{N}$ & $\begin{array}{c}\mathrm{MC} \\
(\% w b)\end{array}$ & RD (min.) & $\begin{array}{c}\mathrm{RT}(\mathrm{oC}) \\
\text { Coded }\end{array}$ & $\begin{array}{c}\mathrm{MC} \\
(\% \text { wb) } \\
\text { Real }\end{array}$ & $\begin{array}{c}\text { RD }(\mathrm{min} .) \\
\text { Real }\end{array}$ & $\begin{array}{c}\text { RT }(\mathrm{oC}) \\
\text { Real }\end{array}$ & $\mathrm{PV}(\mathrm{meg} / \mathrm{kg})$ & $\mathrm{OS}(\mathrm{h})$ \\
\hline 1. & -1 & -1 & -1 & 7 & 10 & 70 & 9.3 & 47.7 \\
2. & -1 & -1 & 1 & 7 & 10 & 110 & 4.3 & 54.7 \\
3. & -1 & 1 & -1 & 7 & 20 & 70 & 4.7 & 51.1 \\
4. & -1 & 1 & 1 & 7 & 20 & 110 & 4.0 & 63.3 \\
5. & 1 & -1 & -1 & 13 & 10 & 70 & 10.2 & 36.3 \\
6. & 1 & -1 & 1 & 13 & 10 & 110 & 8.8 & 50.1 \\
7. & 1 & 1 & -1 & 13 & 20 & 70 & 10.2 & 37.1 \\
8. & 1 & 1 & 1 & 13 & 20 & 110 & 9.7 & 42.4 \\
9. & 1.682 & 0 & 0 & 16 & 15 & 90 & 15.4 & 13.0 \\
10. & -1.682 & 0 & 0 & 4 & 15 & 90 & 3.9 & 58.0 \\
11. & 0 & 1.682 & 0 & 10 & 25 & 90 & 4.5 & 56.3 \\
12. & 0 & -1.682 & 0 & 10 & 5 & 90 & 11.0 & 29.9 \\
13. & 0 & 0 & 1.682 & 10 & 15 & 130 & 4.1 & 62.5 \\
14. & 0 & 0 & -1.682 & 10 & 15 & 50 & 11.0 & 17.6 \\
15. & 0 & 0 & 0 & 10 & 15 & 90 & 13.6 & 24.0 \\
16. & 0 & 0 & 0 & 10 & 15 & 90 & 13.3 & 24.9 \\
17. & 0 & 0 & 0 & 10 & 15 & 90 & 13.9 & 24.6 \\
18. & 0 & 0 & 0 & 10 & 15 & 90 & 14.0 & 24.7 \\
19. & 0 & 0 & 0 & 10 & 15 & 90 & 12.6 & 25.0 \\
20. & 0 & 0 & 0 & 10 & 15 & 90 & 13.1 & 24.2 \\
\hline
\end{tabular}




\section{REFERENCES}

1. Sudhir SD, Deshande US and DK Salunkhe Sesame Oil. In Bailey's Industrial Oil and Fat Product. John Wiley and Son's Inc. New York, 1996.

2. Salunkhe DK, Chava JK, Adsuk RN and S Kadam World Oilseed: Chemistry, Technology and Utilization. Van Nostrand Reinhold, New York, 1992.

3. Lee JY, Lee YS, and EO Choe Effects of Sesamol, Sesamin and Sesamolin Extracted from Roasted Sesame Oil on the Thermal Oxidation of Methyllinoleate. Food Sci and Techn, 2008; 42: 1871-1875.

4. Chang LW , Y en WJ, Huang SC and PD Duh Antioxidant Activity of Sesame Coat. F ood Chem, 2002; 78: 347-354.

5. CBN. Annual Report and Statement of Account for the Year Ended $31^{\text {st }}$ December 2008. Central Bank of Nigeria, 2009; 142-145.

6. Gandhi AP Composition of Oilseeds and Oils and their Nutritional Significance. In Processing and Storage of Oilseeds and Products for Food Uses. Central Institute of Agricultural Engineering. Bhopah M. P. India, 1998; 2: $1-10$.

7. Weiss EA Oil Seed Crop. $2^{\text {nd }}$ Edition Blackwell Longman Group Ltd. USA, 2000.

8. K ikugawa K, Arai M and T K urechi Participation of Sasamol in Stability of Sesame Oil. J. Ame oil Chem Soc, 1983; 60: 1528-1533.

9. O' Brien RD Fats and Oils, Formulating and Processing for Applications. Technical Publishing, Company Inc. Lancaster USA, 1998.

10. Hill SE Comparison: Measuring Oxidative Stability. INF ORM , 1994; 5: 104 109.

11. Holser RA and TA Isbell Effect of Processing Condition on Oxidative Stability of Meadow Foam Press Oil. J. Ame Oil Chem Soc, 2000; 79: 1051 1052.

12. Abou-Charbia HA, Shehata $A A$ and $F$ Shahidi Effect of Processing on Oxidative Stability and Lipid Classes of Sesame Oil. Food research international, 2000; 33: 331-340. 
13. Elleuch $M$, Besbes $S$, Roiseux $O$, Blecker $C$ and $H$ Attia Quality Characteristics of Sesame Seed and bye Products. F ood Chem, 2007; 103: 641650 .

14. Lee SW, J eung MK, Park MH, Lee SY and J Lee Effect of Roasting Conditions of Sesame Seeds on the Oxidative Stability of Pressed Oil During Thermal Oxidation. F ood C hem, 2010; 118: 681-685.

15. Tashiro TY, O sawa T and M Namiki Characteristics of Sesame Varieties. J. Ame Oil Chem Soc, 1990; 67: 507 - 510.

16. Young KM and $\mathrm{H}$ J eong Optimisation of Batch Expression of Sesame Oil. J. Korean Soc of F ood and Nut, 1995; 24: $785-789$.

17. Akinoso R, Igbeka J C and TMA Olayanju Process Optimization of Oil Expression from Sesame Seed (Sesamum indicum Linn.). Agric Eng Int : the CIGR Ejournal, 2006; FP 06 011. Vol. VIII.

18. Mullen $\mathrm{K}$ and DM Ennis Rotatable designs in product development. Food Tech, 1977; 7: 74:80.

19. ASABE. Moisture Measurement-Peanuts. American Society of Agricultural Engineers AS AE S410.1 DEC 1982 (R2008) 679-680.

20. Akinoso R and J C I gbeka Optimisation of Oil Expression from Palm Kernel. J. Food Sci Tech, 2007; 44: 360-362.

21. AOCS. The Official Methods and Recommended Practices of the American Oil Chemists' Society, $19975^{\text {th }}$ Edi. Champaign IL: American Oil Chemists Society, 1997.

22. Matsushita $\mathrm{S}$ Peroxide Value Determining Test for Oils and Fats www.FreePatents Online.com, 1978.

23. Y oshida H and S Takagi Effect of Seed Roasting Temperature and Time on the Quality Characteristics of Sesame (Sesame indicum) Oil. J. Sci of F ood and Agric, 1997; 75: 34- 38.

24. M ohsenin NN Thermal properties of foods and agricultural materials. Gordon and Breach Science, New York, 1980.

25. Hui YH Edible Oil and Fat Products Processing Technology. In Bailey's Industrial Oil and Fat Products, Vol. 4. John Wiley and Son's Inc. New York, 1996. 
26. Lee $\mathrm{Y}, \mathrm{Oh} \mathrm{S}, \mathrm{Chang} \mathrm{J}$ and I K im Chemical Composition and Oxidative Stability of Safflower Oil Prepared from Safflower Seed Roasted with Different Temperatures. F ood Chem, 2004; 84: 1-6.

27. Wu WH The Contents of Lignans in Commercial Sesame Oils of Taiwan and their Changes During Heating. F ood C hem, 2007; 104: 341-344.

28. Y en GC and SL Shyu Oxidative Stability of Sesame Oil Prepared from Sesame with Different Roasting Temperature. F ood Chem, 1989; 31: 215-224.

29. Shahidi F and M Naczk Phenolics in Food and Nutraceuticals. CRC press, Florida, 2004. 